\title{
Supermarket and fast-food outlet exposure in Copenhagen: associations with socio-economic and demographic characteristics
}

\author{
Chalida M Svastisalee ${ }^{1,2, *}$, Helene Nordahl', Charlotte Glümer ${ }^{3}$, Bjørn E Holstein ${ }^{1,2}$, \\ Lisa M Powell ${ }^{4}$ and Pernille Due ${ }^{2}$ \\ 'Department of Public Health, University of Copenhagen, Øster Farimagsgade 5, PO Box 2099, Copenhagen K, \\ Denmark 1014: ${ }^{2}$ National Institute of Public Health, University of Southern Denmark, Øster Farimagsgade \\ 5A - 2nd Floor, Copenhagen K, Denmark 1399: ${ }^{3}$ Research Center for Prevention and Health, Glostrup \\ University Hospital, Glostrup, Denmark: ${ }^{4}$ Institute for Health and Research Policy, University of Illinois-Chicago, \\ Chicago, IL, USA
}

Submitted 27 August 2010: Accepted 25 February 2011: First published online 19 April 2011

\begin{abstract}
Objective: To investigate whether exposure to fast-food outlets and supermarkets is socio-economically patterned in the city of Copenhagen.

Design: The study was based on a cross-sectional multivariate approach to examine the association between the number of fast-food outlets and supermarkets and neighbourhood-level socio-economic indicators. Food business addresses were obtained from commercial and public business locators and geocoded using a geographic information system for all neighbourhoods in the city of Copenhagen ( $n$ 400). The regression of counts of fast-food outlets and supermarkets $v$. indicators of socio-economic status (percentage of recent immigrants, percentage without a high-school diploma, percentage of the population under 35 years of age and average household income in Euros) was performed using negative binomial analysis.

Setting: Copenhagen, Denmark.

Subjects: The unit of analysis was neighbourhood ( $n$ 400).

Results: In the fully adjusted models, income was not a significant predictor for supermarket exposure. However, neighbourhoods with low and mid-low income were associated with significantly fewer fast-food outlets. Using backwise deletion from the fully adjusted models, low income remained significantly associated with fast-food outlet exposure (rate ratio $=0 \cdot 66-0 \cdot 80$ ) in the final model.

Conclusions: In the city of Copenhagen, there was no evidence of spatial patterning of supermarkets by income. However, we detected a trend in the exposure to fast-food outlets, such that neighbourhoods in the lowest income quartile had fewer fast-food outlets than higher-income neighbourhoods. These findings have similarities with studies conducted in the UK, but not in the USA. The results suggest there may be socio-economic factors other than income associated with food exposure in Europe.
\end{abstract}

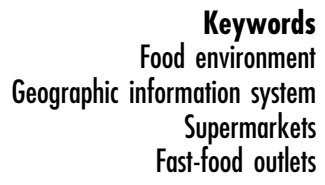

Typical of other Western countries, Denmark has seen significant increases in the prevalence of obesity and overweight over the past decades ${ }^{(1-4)}$, posing increased risk of a number of chronic diseases such as CHD and diabetes ${ }^{(5-9)}$. Two major lifestyle factors contributing to obesity, inadequate physical activity and energy-dense diets, have been investigated extensively ${ }^{(10-14)}$ and in developed countries these behaviours are found to be inversely related to socioeconomic status ${ }^{(15-21)}$. There is some evidence suggesting similar socio-economic patterning of low exercise and dietary behaviours in the Danish context ${ }^{(17,21-23)}$. Within Copenhagen, the tendency to consume fast food is high for residents living in areas of low social class and the propensity for overweight is significant among women living in poorer neighbourhoods ${ }^{(22)}$. Because these major contributors are spatially patterned, there is increasing scientific interest in investigating how access to exercise space or to food outlets contributes to obesity ${ }^{(12,24-26)}$.

Of concern is whether disparities across neighbourhoods are predictive of access to food, which potentially impacts the ability of residents to eat healthily. A review conducted by Larson et al. ${ }^{(27)}$ of studies performed in the USA showed those living in either low-income ${ }^{(28-32)}$ or minority ${ }^{(29,30,32-36)}$ areas to have poor access to supermarkets, and that these 
patterns tend to be nationwide ${ }^{(32)}$. On the other hand, Larson $e t a l .^{(27)}$ as well as Fraser $e t a l .{ }^{(37)}$ showed that fastfood outlets, characterized as places where energy-dense foods are sold, tend to be found in greater proportion in predominantly low-income neighbourhoods ${ }^{(28,38,39)}$ and these patterns are also reflected at a national level ${ }^{(40)}$.

In other parts of the world, results of studies investigating disparities in the food environment are mixed ${ }^{(37,41)}$. While some studies conducted in Australia $^{(42)}$ and New Zealand ${ }^{(43)}$ support US findings that low-income areas have poor access to supermarkets but greater access to fastfood outlets, other studies in major cities in the $\mathrm{UK}^{(44)}$, Canada ${ }^{(45-47)}$ and Australia ${ }^{(48)}$ found low-income neighbourhoods to have equal if not better access to supermarkets than more affluent ones. Additionally, investigations conducted in the UK have been inconsistent, finding no social patterning of out-of-home outlets in general ${ }^{(49)}$ compared with the disproportional distribution of multinational food chains ${ }^{(50)}$.

Aside from studies conducted in the UK, there are no other area-level explorations of the food environment in other European countries, despite the growth in the number of fast-food outlets ${ }^{(51)}$ and displacement of small grocers by large chain supermarkets ${ }^{(52,53)}$ over the past decade. This change in the food shopping landscape may also have an impact on who has access to healthy food, resulting in alterations in eating behaviour.

We are particularly interested in investigating the distribution of food outlets in a Scandinavian context, as here there tends to be relatively less income inequality ${ }^{(54)}$ than in the USA, Canada and Australia, where a large part of the research regarding the impact of food environments on health occurs. Explorations of neighbourhood food environments have not been readily conducted in Denmark. Thus the purpose of the present study was to evaluate whether neighbourhood-level socio-economic indicators such as income, education and immigration status are predictive of supermarket and fast-food outlet exposure in the capital city of Copenhagen.

\section{Methods}

\section{Location}

Copenhagen is the capital of Denmark $\left(88.25 \mathrm{~km}^{2}\right)$, containing 518574 residents within the city boundary ${ }^{(55)}$. Population density of the city area alone is $5876 \cdot 2 / \mathrm{km}^{2}$. Approximately 1.16 million people live in the greater urban area ${ }^{(56)}$, which encompasses almost one-fifth of Denmark's 5.5 million people. Thus Copenhagen is not only the largest city, but also the most densely populated and ethnically diverse area in the country ${ }^{(55,57)}$.

\section{Neighbourbood boundaries}

Administrative map boundaries for all neighbourhoods in the city of Copenhagen ( $n$ 400) were supplied by the
Danish Map and Cadastre (Danish Map and Cadastre, 2006; www.kms.dk). Neighbourhoods for the present analysis are based on the 'rode', which is the smallest administrative unit in Copenhagen proper. Rodes are municipally defined enumeration districts originally used for taxation purposes and serve as the basis for school and tax allocation ${ }^{(58)}$. The average area of one rode is small, approximately $0.2 \mathrm{~km}^{2}$; rodes are readily supplied with statistical information by the City and are unique to Copenhagen. In order to prevent potential identification of individuals, we excluded neighbourhoods with sample populations equal to one ( $n$ 10). We also eliminated two rodes due to missing outcome measures. Thus, the total number of rodes included in the analysis was 388 out of a total possible 400 neighbourhoods. Recognizing that residents may shop in other neighbouring areas for food due to the small size of each rode, we conducted an analysis using larger units (school districts), which would possibly take care of the lack of access within smaller units. However, a reduction from 400 to sixty-seven analytical units resulted in too few samples per cell.

\section{Socio-economic data}

We used 2006 neighbourhood-level socio-economic population information from Statistics Denmark, the provider of national statistics data (Statistics Denmark, 2006; www.dst.dk). Information from Statistics Denmark is based on full population registry data, which are consistently monitored.

We selected socio-economic variables according to population characteristics demonstrated in the literature to be especially vulnerable to having poor access to healthy food ${ }^{(27-32,34-36,40)}$. Low education was defined by the percentage of 16- to 85-year-olds in each neighbourhood lacking a high-school diploma. The recent immigration variable was defined by immigration status, as the percentage of first generation non-Danish nationals (excluding descendents) living in the neighbourhood. Although age is not classically defined as a risk factor for poor access to food, we included an age group variable for several reasons. First, age groups under 35 years have been specifically identified by the fast-food industry as the most frequent visitors to fast-food outlets in Denmark $^{(59)}$. Second, the population under age 20 years of age has been identified as containing the fastest-growing number of frequent consumers of fast food ${ }^{(60)}$. As it is likely that these two groups are related in terms of eating behaviour, we defined the youth variable by the percentage of residents per neighbourhood under 35 years of age. Income was defined by the average taxable income for an individual and any co-habiting partner. We calculated the average neighbourhood income in Euros based on the population aged $16-85$ years and categorized it according to quartiles: low $(<€ 23000)$, mid-low ( $€ 23$ 000-25 750), mid-high ( $€ 25750-28500)$ and high $(>€ 28500)$. Statistics Denmark considers taxable income to contain individual's gross income minus labour 
market contributions, special pension contributions and income deductions ${ }^{(56)}$. For all variables except income, we used mean percentages as comparative cut-off points for analysis.

\section{Food outlets}

The addresses of food outlets were obtained from the Danish Central Business Registry (CVR), which is the national tax database for all registered businesses in Denmark ${ }^{(61)}$. The CVR contains categorization capabilities such that we obtained food business information using standardized classification for economic activities in the European Union (Table 1). We defined our search by NACE (Nomenclature statistique des activités économiques dans la Communauté européenne; Statistical Classification of Economic Activities in the European Community) $\operatorname{codes}^{(62)}$, with postal code restriction to include only relevant postal codes within the city of Copenhagen and date of business establishment in 2006 or earlier. Based on this initial search, we retrieved 889 addresses. In order to investigate data consistency between various commercial sources of business data, we also supplemented the initial database with addresses purchased from a commercial business locater ${ }^{(63)}$ and used a keyword search based on the NACE code definitions (see Table 1) using the telephone company (Teledanmark, 2006; www.nnmarkedsdata.dk) and compared them against the CVR. There was $68.5 \%$ and $87.0 \%$ overlap, respectively, between the tax registry and the other two data sources. A one-in-five sub-sample of addresses were additionally checked using two map search engines, Google Maps (http://www.googlemaps.dk) and Krak (http:// www.krak.dk), to ensure physical presence (70\% and $89 \%$ overlap, respectively). Based on these database comparisons, we eliminated any double addresses or those based on keyword search that did not meet initial search criteria. A total of 869 addresses remained. We excluded another sixty-seven addresses that were categorized as 'not found' or listed as a personal address in at least three of the five data sources, one of which included one of the map search engines. Based on the resulting 802 addresses, we then created two business categories based on the NACE code numbers supplied by CVR and as shown in Table 1: (i) retail supermarkets (which include the entire NACE code range of retail, discount, large chain and small independent supermarkets); and (ii) fastfood outlets and grill bars (supplied by one NACE code to include all chain and privately owned non-table service venues selling burgers, pizza, shawarma, hotdogs and combined ice cream/grill bars). We also conducted a food outlet street inventory on a sub-sample of neighbourhoods in two boroughs to check for physical presence. Despite high correspondence between the secondary sources of food outlet information and validation by street inventory (positive predictive values $>0 \cdot 80$ ), we did not include cafés or businesses described as food kiosks in the final analysis. Our street validation revealed that a café could be a true coffee house, a bar or a pub. Additionally, kiosks could also consist of Western Union money exchange sites, tobacco and alcohol retail outlets, Internet cafés or gambling sites, in addition to the conventional convenience store.

\section{Food outlet outcome measurements}

Food outlet addresses were geocoded and visualized using ArcGIS software version 9·1 (ESRI, Redlands, CA, USA), applying road and highway map data (Krak DK, 2005) as well as administrative neighbourhood boundaries (Danish Map Cadastre, 2006). As we included 388 of the total 400 neighbourhood rodes, not all of the food outlets were used in the analysis. Thus, in total, 802 fast-food outlets and supermarkets were geocoded, and $97 \%$ ( $n 790$ ) of the food outlets were used in the analysis. Counts of each outcome measure were developed based on total number of geocoded addresses in each category per neighbourhood boundary.

\section{Statistical analyses}

We examined how neighbourhood-level socio-economic indicators were associated with the number of fast-food outlets and supermarkets. As initial analyses by Poisson regression indicated overdispersion by a deviance measure greater than one ${ }^{(64)}$, we employed negative binomial analysis in two separate models to analyse neighbourhood exposure to (i) supermarkets and (ii) fast-food outlets, universally controlling for differences in neighbourhood population size. All analyses were conducted with the SAS statistical software package version $9 \cdot 1$ (SAS Institute, Cary, NC, USA).

We report results from both crude and fully adjusted models as rate ratios transformed from beta estimates in a negative binomial analysis ${ }^{(32)}$. In the crude model, we

Table 1 NACE codes and examples of fast-food outlets and supermarkets

\begin{tabular}{llcl}
\hline Category & \multicolumn{1}{c}{ 2006 NACE definition } & NACE code & Example \\
\hline Retail supermarkets & Retail sale of food and beverages & 52.11 .10 & Quick Save \\
& Supermarket & 52.11 .30 & Irma, Superbest, Fakta \\
& Discount food store & 52.11 .40 & Aldi \\
& Food warehouse & 52.12 .10 & Føtex, Kvickly \\
Fast-food outlets & Cafeteria, hotdog stand, grill bar, ice cream stand & 55.30 .20 & Pizza Tony's, Master Grill \\
\hline
\end{tabular}

NACE, Nomenclature statistique des activités économiques dans la Communauté européenne (Statistical Classification of Economic Activities in the European Community). 


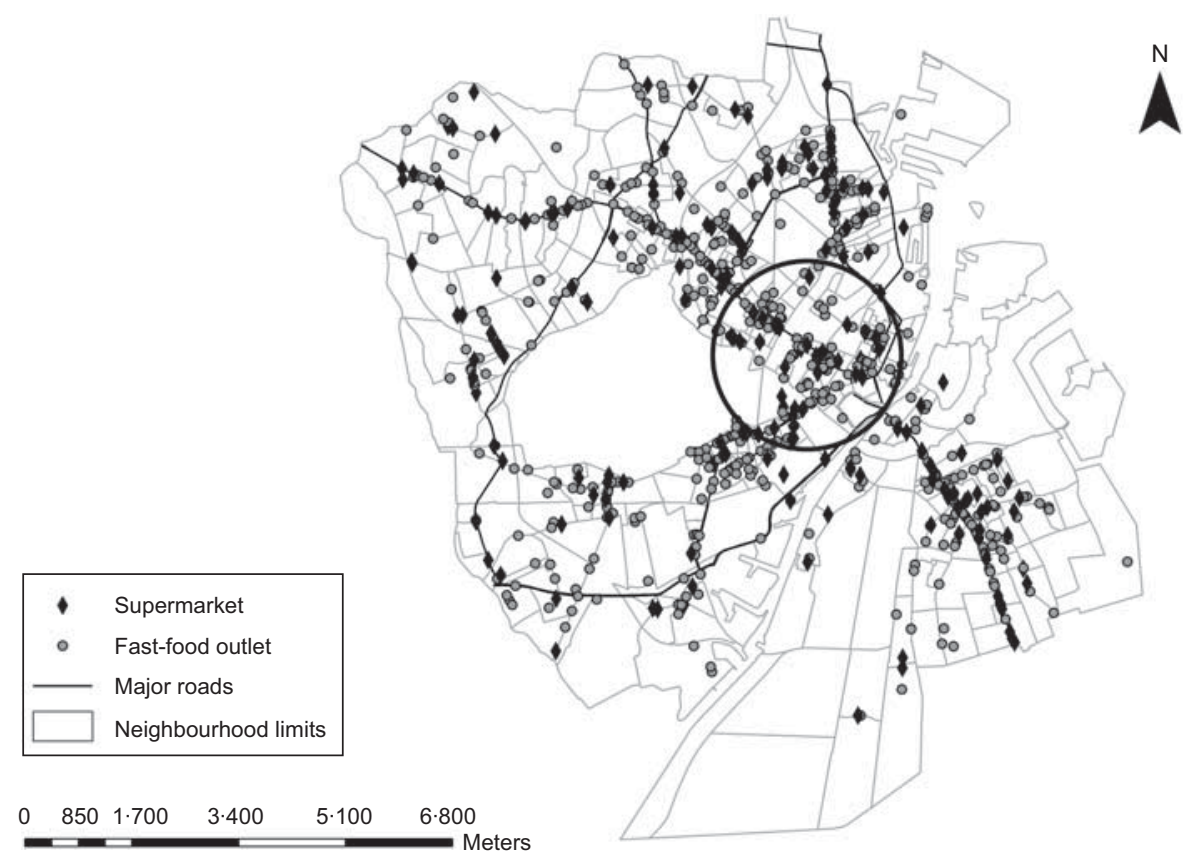

Fig. 1 Distribution of supermarkets and fast-food outlets in Copenhagen, Denmark, 2006

tested each variable singularly to determine the relationship with either supermarket or fast-food outlet exposure in each neighbourhood. In order to retain the most meaningful variables associated with food outlet exposure, we employed backwise deletion from the fully adjusted model in stepwise fashion. For each step of deletion, we manually removed the covariate with the least statistical significance until the model only included variables significantly associated with food outlet exposure. All models were controlled for differences in population size.

\section{Results}

Figure 1 shows the distribution of supermarkets and fastfood outlets in the city of Copenhagen represented by the 400 rodes (in grey outline). While fast-food outlets and supermarkets tend to be more densely located in the city centre (represented by the circle), the greatest number of both supermarkets and fast-food outlets are placed along the major road arteries of the city (selected roads in heavy outline).

Among 388 neighbourhoods used for analysis to examine the association between either supermarket or fast-food outlet exposure and socio-economic indicators in the city of Copenhagen, a total of 199 supermarkets and 591 fast-food outlets were located within the study boundaries (Table 2). Almost twice as many neighbourhoods in Copenhagen lacked a supermarket $(65 \%)$ as lacked a fast-food outlet (35\%). Overall, there was a fairly wide distribution of residents, with average population density of $14796 / \mathrm{km}^{2}$ per rode (range: $671-64383 / \mathrm{km}^{2}$ ).
The Copenhagen neighbourhoods tended to be primarily composed of residents who rent their home (75\%), with low proportions of recent immigrants (13\%). On average, $28 \%$ of the residents did not have a high-school diploma and the average taxable income in 2006 for Copenhagen was approximately $€ 26000$ (range: 0 to $€ 46000$ ).

Table 3 shows the results for supermarket exposure expressed as rate ratios based on negative binomial analysis. The results show that supermarkets are not spatially patterned according to neighbourhood income levels. In fact, none of the other socio-economic variables alone or in the fully adjusted models was significantly associated with supermarket exposure. There was also no evidence of a relationship between supermarket exposure and indicators of socio-economic deprivation even after having conducted backwise elimination from the fully adjusted supermarket exposure models in order to extract the most meaningful and significant variables.

The results for unadjusted, mutually adjusted and backwise elimination models for fast-food outlet exposure are illustrated in Table 4. We noted an income gradient in fast-food outlet exposure, such that neighbourhoods with low and mid-low income had less exposure than wealthier counterparts. These findings were significant in the mutually adjusted model. Neighbourhoods with a greater proportion of youth had marginally statistically significant greater exposure to fast-food outlets (rate ratio $=1 \cdot 30$ ) than comparison areas. In the final backwise deletion model, youth and income variables were retained, with the low and mid-low income quartiles significantly having $44 \%$ less exposure to fast-food outlets than the highest income referent. 
Table 2 Frequency of supermarkets and fast-food outlets, and socio-economic and demographic characteristics of neighbourhoods, Copenhagen, Denmark, 2006

\begin{tabular}{|c|c|c|}
\hline & $n$ or Mean & $\%$ or SD \\
\hline Number of neighbourhoods & 388 & \\
\hline Number of supermarkets & 199 & \\
\hline Neighbourhoods without supermarkets & 253 & $64 \cdot 9$ \\
\hline Neighbourhoods with one or more supermarket & 135 & $34 \cdot 6$ \\
\hline Number of fast-food outlets & 591 & \\
\hline Neighbourhoods without fast-food outlets & 136 & $34 \cdot 9$ \\
\hline Neighbourhoods with one or more fast-food outlet & 252 & $64 \cdot 6$ \\
\hline Total population per rode & 1297 & $705 \cdot 4$ \\
\hline Population density per rode $\left(/ \mathrm{km}^{2}\right)$ & 14796 & 11503 \\
\hline Mean area $\left(\mathrm{km}^{2}\right)$ & 0.2 & 0.3 \\
\hline Recent immigrants (mean proportion) & $12 \cdot 8$ & $8 \cdot 2$ \\
\hline Lacking high-school diploma (mean proportion) & $28 \cdot 4$ & $10 \cdot 8$ \\
\hline Under 35 years of age (mean proportion) & $12 \cdot 6$ & $2 \cdot 9$ \\
\hline Average taxable individual income $(€)$ & 25889 & $5232 \cdot 8$ \\
\hline
\end{tabular}

Data are expressed as total number and percentage or mean and standard deviation.

Table 3 Rate ratio (RR) and $95 \%$ confidence interval for supermarket exposure according to sociodemographic indicator, Copenhagen, Denmark, 2006†

\begin{tabular}{|c|c|c|c|c|c|c|}
\hline \multirow[b]{2}{*}{ Sociodemographic indicator } & \multicolumn{2}{|c|}{ Unadjusted model } & \multicolumn{2}{|c|}{ Mutually adjusted model } & \multicolumn{2}{|c|}{ Final model after backward reduction } \\
\hline & $\mathrm{RR}$ & $95 \% \mathrm{Cl}$ & $\mathrm{RR}$ & $95 \% \mathrm{Cl}$ & $\mathrm{RR}$ & $95 \% \mathrm{Cl}$ \\
\hline Recent immigrant & $0 \cdot 74$ & $0.51,1.07$ & 0.88 & $0.52,1.47$ & & \\
\hline No high-school diploma & 0.73 & $0.52,1.02$ & 0.72 & $0 \cdot 46,1 \cdot 15$ & 0.72 & $0 \cdot 47,1 \cdot 10$ \\
\hline Youth & 0.95 & $0 \cdot 68,1 \cdot 34$ & 0.93 & $0 \cdot 64,1 \cdot 36$ & & \\
\hline \multicolumn{7}{|l|}{ Income $(€)$} \\
\hline Low & $0 \cdot 81$ & $0.49,1.35$ & $1 \cdot 23$ & $0.60,2 \cdot 54$ & $1 \cdot 08$ & $0 \cdot 59,2 \cdot 00$ \\
\hline Mid-low & 0.98 & $0.60,1.60$ & $1 \cdot 25$ & $0.69,2 \cdot 26$ & $1 \cdot 18$ & $0.68,2.02$ \\
\hline Mid-high & $1 \cdot 16$ & $0 \cdot 72,1 \cdot 86$ & $1 \cdot 29$ & $0 \cdot 78,2 \cdot 13$ & $1 \cdot 28$ & $0 \cdot 78,2 \cdot 08$ \\
\hline High (ref.) & $1 \cdot 00$ & - & 1.00 & - & 1.00 & - \\
\hline
\end{tabular}

tAll models have been adjusted for population size/rode area.

Table 4 Rate ratio (RR) and $95 \%$ confidence interval for fast-food outlet exposure according to sociodemographic indicator, Copenhagen, Denmark, 2006+

\begin{tabular}{|c|c|c|c|c|c|c|}
\hline \multirow[b]{2}{*}{ Sociodemographic indicator } & \multicolumn{2}{|c|}{ Unadjusted model } & \multicolumn{2}{|c|}{ Mutually adjusted model } & \multicolumn{2}{|c|}{ Final model after backward reduction } \\
\hline & $\mathrm{RR}$ & $95 \% \mathrm{Cl}$ & RR & $95 \% \mathrm{Cl}$ & $\mathrm{RR}$ & $95 \% \mathrm{Cl}$ \\
\hline Recent immigrant & $1 \cdot 01$ & $0 \cdot 78,1 \cdot 32$ & $1 \cdot 27$ & $0.90,1 \cdot 78$ & & \\
\hline No high-school diploma & 0.83 & $0.65,1.06$ & 0.96 & $0.69,1.34$ & & \\
\hline Youth & $1 \cdot 12$ & $0.88,1.44$ & $1 \cdot 30$ & $0.99,1.72$ & $1 \cdot 29$ & $0.99,1.68$ \\
\hline \multicolumn{7}{|l|}{ Income $(€)$} \\
\hline Low & 0.74 & $0.52,1.06$ & $0.56^{*}$ & $0.34,0.92$ & $0.66^{*}$ & $0.46,0.97$ \\
\hline Mid-low & 0.75 & $0.53,1.06$ & $0.63^{*}$ & $0.41,0.98$ & $0 \cdot 66^{*}$ & $0.45,0.96$ \\
\hline Mid-high & $0 \cdot 84$ & $0 \cdot 60,1 \cdot 19$ & $0 \cdot 81$ & $0 \cdot 56,1 \cdot 16$ & $0 \cdot 80$ & $0 \cdot 56,1 \cdot 13$ \\
\hline High (ref.) & $1 \cdot 00$ & - & $1 \cdot 00$ & - & $1 \cdot 00$ & - \\
\hline
\end{tabular}

*Model was statistically significant at the 0.01 level.

tAll models have been adjusted for population size/rode area.

\section{Discussion}

The present study is the first to explore the socio-economic patterning of supermarkets and fast-food outlets in a major city in a Scandinavian country. In contrast to findings in the USA, which tend to show low-income areas have less access to supermarkets and greater access to fast-food outlets ${ }^{(27)}$, we found no evidence of socioeconomic patterning of supermarkets in Copenhagen and found that fast-food restaurants were less available in low-income neighbourhoods.

\section{Supermarket exposure}

The findings of no association with socio-economic characteristics for supermarket exposure support previous research conducted in other cities such as Cardiff, Leeds and Bradford in the $\mathrm{UK}^{(44)}$, Montreal and Edmonton in Canada ${ }^{(45-47)}$ and Brisbane in Australia ${ }^{(48)}$, which found 
low-income areas having equal if not better access to supermarkets than more affluent ones.

\section{Fast-food exposure}

In general, neighbourhoods with a high proportion of recent immigrants or a high proportion of residents without a high-school diploma were not significantly associated with fast-food outlet exposure. In the unadjusted model, while no single variable was significantly associated with fast-food outlet exposure, we observed low-income neighbourhoods had less exposure to fastfood outlets than the high-income comparison. This association became significant in the mutually adjusted model. Additionally, exposure was higher for neighbourhoods with greater proportions of youth, although this association was marginally significant. When the recent immigrant and low education variables were removed from the model, retaining only the youth variable, the income patterning of fast-food outlet exposure remained such that low and mid-low neighbourhoods had only $46 \%$ of fast-food outlet exposure compared with high-income areas. Contrary to findings from the $\mathrm{USA}^{(27)}$, Australia ${ }^{(42)}$, New Zealand ${ }^{(43)}$ and the $\mathrm{UK}^{(50)}$, these findings suggest that low-income areas in Copenhagen have less exposure to fast-food outlets than wealthier ones. While there seems to be a greater body of literature that supports greater exposure to fast-food outlets in low-income neighbourhoods, Macintyre et al. found no social patterning of out-of-home outlets in Glasgow ${ }^{(49)}$.

There may be several reasons for the variability in study results. First, we suspect that there are methodological differences in defining measures of spatial access and scale. One limitation of the present study is that we used the number of outlets as an indication of exposure. We acknowledge that there are other approaches to express measures of spatial access, such as density or proximity ${ }^{(65)}$, which may produce different study results. Another limitation is represented in definitions of neighbourhood scale. While the rode unit of geographical measure was appropriate for an administrative characterization of neighbourhood, it is unique to Copenhagen and cannot be used as a defining scale for the rest of the country. Despite its relatively small size for the measurement of statistical reporting ${ }^{(58)}$, it is still much larger than an average census block in the USA, the smallest geographical unit for census data ${ }^{(66)}$. Second, there also may be country differences in transport access to fastfood outlets. There have been several studies conducted elsewhere showing that those living in poor areas are greatly impacted by the food environment, especially if they are lacking adequate transportation ${ }^{(42,67,68)}$. Given that public transportation is highly accessible in Copenhagen, with relatively low levels of car ownership ${ }^{(55)}$, transportation access to food outlets may not be of the same concern as in other places lacking adequate transport. A third reason for variability in study results could be due to differences in how fast-food outlets were defined in our study. Fraser et al. ${ }^{(37)}$ suggest that all types of fast-food source should be included in analyses so that associations are based on true representations of the food environment. While we liberally included private and chain-owned fast-food outlets within a specific NACE code in the current study, our analysis did not include other non-traditional sources of fast food (cafés or kiosks) in order to safeguard against misclassification error. Nevertheless, we recognize that study findings may underestimate associations between fast-food outlet exposure and socio-economic patterning. In the same vein, the overall quality of our data was high and consisted of multiple sources of secondary data in addition to street validation; however, we recognize validation of secondary sources of data information is a constant challenge and continued efforts to improve data quality are warranted $^{(69)}$. Perhaps the greatest factor influencing the results may be the relatively low income disparity in Denmark, as indicated by its Gini index of $0 \cdot 25^{(70)}$. Denmark is a welfare state and income is significantly redistributed through taxation so that higher income earners pay higher taxes, resulting in smaller differences between wealthy and non-wealthy residents ${ }^{(54)}$. In comparison, the USA has a Gini index of $0 \cdot 41^{(71)}$, indicating greater differences between low and high incomes, and may offer one explanation for why income-based disparities in access to supermarkets, for instance, are more visible in the USA. In contrast, the UK $(0 \cdot 36)$ and Australia $(0 \cdot 35)^{(71)}$ have Gini indices lower than that of the USA, which may also contribute to the mixed findings associated with income patterning of the distribution of food outlets. In the future, in may be interesting to conduct cross-national comparisons to examine whether the distribution of food outlets may be differentiated according to Gini index.

In their recent review of measures of the food environment, Charreire et al. ${ }^{(65)}$ highlighted that future research needs to address the challenge of characterizing multiple dimensions of access that incorporate social and well as economic aspects of access.

\section{Strengths and limitations}

The study presents new emerging results relevant for environmental influences on eating behaviour and health in a Scandinavian context, which have very different socio-economic structures and urban form to the USA. Merits of the study include the use of representative register-based information and various sources of address information to validate the physical presence of food outlet location.

In further addressing study limitations, we did not conduct a comprehensive analysis of the food environment to include other types of food outlet such as greengrocers, food kiosks and convenience stores, specialty food shops (bakeries or deli shops), cafés, service 
restaurants or other places where ready-prepared food is purchased. Although these categories of food outlet are relatively fewer in number compared with the combined total of supermarkets and fast-food outlets in Denmark ${ }^{(61)}$, it may be worthwhile to investigate the impact of cafés and service restaurants on the local food environment, given the increasing trend towards frequenting cafés ${ }^{(59)}$. We also were limited to socio-economic information made available by national statistical databases, and we acknowledge that other socio-economic characteristics associated with food access, such as car ownership or public transportation, which may impact travel to food outlets, or potential indicators of neighbourhood need in a Scandinavian context ${ }^{(72)}$ may impact the results and should be considered in future studies. As our study is ecological in approach and not linked to individual information, the results are limited in terms of explanatory capacity and do not allow for the inference of associations with behavioural outcomes. Additionally, the study focuses only on one city in Denmark, albeit the capital city, which allows us to explore a much more ethnically and socio-economically diverse population than the rest of the country. Study results may be different if the food environment of the entire country were considered, as populations in rural areas of Denmark tend to be more homogeneous socio-economically ${ }^{(54)}$. Finally, initial tests (data not shown) indicated no differences in supermarket or fast-food outlet exposures at each level of income, nor were there notable differences in characteristics between areas containing or absent of food outlets. We did not conduct an income-stratified analysis because of lack of sample size required for an analysis of count data. Perhaps results would be more pronounced with a whole-country sample, or a stratified analysis using a continuous exposure measure.

\section{Implications}

The facts that our analysis does not reveal disparities in food access and that these findings are different from previous studies in the USA suggest the need for evidence in other European countries regarding food outlet exposure. With regard to policy implementation, results of the study also confirm the need for country- or culturally appropriate measures of access and socio-economic disparity. Finally, more detailed analyses linking the built environment with individual dietary behaviour will provide evidence on the importance of these factors for policy makers.

\section{Conclusions}

On the basis of the present analysis, we conclude that there is no association between supermarket exposure and socio-economic indicators in Copenhagen. However, we did detect a patterning of fast-food outlets, such that neighbourhoods in the lowest income quartile had less exposure to fast-food outlets than higher income ones.
These findings are supportive of evidence found in the $\mathrm{UK}^{(49,73)}$ but do not agree with study trends found in the USA. Therefore the results suggest there may be other socio-economic patterns of neighbourhood food exposure within a European context.

\section{Acknowledgements}

This work was made possible through grants funded by the Danish Graduate School in Public Health Science (GRASPH) at the University of Copenhagen, The Oticon Foundation, the Danish Health Fund, the Danish Heart Foundation and the Nordea Fund. None of the authors has a conflict of interest. C.M.S., H.N., C.G., B.E.H. and P.D. were responsible for conception of the study, study design and set-up. H.N. and C.G. were responsible for data collection and processing. C.M.S. drafted the manuscript. H.N., C.G., B.E.H., L.M.P. and P.D. assisted with drafting the manuscript. All authors were involved with data interpretation and critical revisions of the paper, and provided approval for publication.

\section{References}

1. Heitmann BL (2000) Ten-year trends in overweight and obesity among Danish men and women aged 30-60 years. Int J Obes Relat Metab Disord 24, 1347-1352.

2. Lissau I (2004) Overweight and obesity epidemic among children. Answer from European countries. Int J Obes Relat Metab Disord 28, Suppl. 3, S10-S15.

3. Due P, Heitmann BL \& Sorensen TI (2007) Prevalence of obesity in Denmark. Obes Rev 8, 187-189.

4. Matthiessen J, Velsing Groth M, Fagt S et al. (2008) Prevalence and trends in overweight and obesity among children and adolescents in Denmark. Scand J Public Health 36, 153-160.

5. Wing RR, Goldstein MG, Acton KJ et al. (2001) Behavioral science research in diabetes: lifestyle changes related to obesity, eating behavior, and physical activity. Diabetes Care 24, 117-123.

6. Alexander JK (2001) Obesity and coronary heart disease. Am J Med Sci 321, 215-224.

7. Norman JE, Bild D, Lewis CE et al. (2003) The impact of weight change on cardiovascular disease risk factors in young black and white adults: the CARDIA study. Int J Obes Relat Metab Disord 27, 369-376.

8. Schulze MB \& Hu FB (2005) Primary prevention of diabetes: what can be done and how much can be prevented? Annu Rev Public Health 26, 445-467.

9. Gittelsohn J \& Kumar MB (2007) Preventing childhood obesity and diabetes: is it time to move out of the school? Pediatr Diabetes 8, Suppl. 9, 55-69.

10. Popkin BM (2009) What can public health nutritionists do to curb the epidemic of nutrition-related noncommunicable disease? Nutr Rev 67, Suppl. 1, S79-S82.

11. Ross R \& Bradshaw AJ (2009) The future of obesity reduction: beyond weight loss. Nat Rev Endocrinol 5, 319-325.

12. Sallis JF \& Glanz K (2009) Physical activity and food environments: solutions to the obesity epidemic. Milbank Q 87, 123-154.

13. Sodlerlund A, Fischer A \& Johansson T (2009) Physical activity, diet and behaviour modification in the treatment of 
overweight and obese adults: a systematic review. Perspect Public Health 129, 132-142.

14. Wilson DK (2009) New perspectives on health disparities and obesity interventions in youth. J Pediatr Psychol 34, 231-244.

15. Winkleby MA, Kraemer HC, Ahn DK et al. (1998) Ethnic and socioeconomic differences in cardiovascular disease risk factors: findings for women from the Third National Health and Nutrition Examination Survey, 1988-1994. JAMA 280, 356-362.

16. Irala-Estevez JD, Groth M, Johansson L et al. (2000) A systematic review of socio-economic differences in food habits in Europe: consumption of fruit and vegetables. Eur J Clin Nutr 54, 706-714.

17. Varo JJ, Martinez-Gonzalez MA, De Irala-Estevez J et al (2003) Distribution and determinants of sedentary lifestyles in the European Union. Int J Epidemiol 32, 138-146.

18. Cubbin C, Sundquist K, Ahlen H et al. (2006) Neighborhood deprivation and cardiovascular disease risk factors: protective and harmful effects. Scand J Public Health 34, 228-237.

19. Hanson MD \& Chen E (2007) Socioeconomic status and health behaviors in adolescence: a review of the literature. J Behav Med 30, 263-285.

20. Rasmussen M, Krolner R, Klepp KI et al. (2006) Determinants of fruit and vegetable consumption among children and adolescents: a review of the literature. Part I: quantitative studies. Int J Behav Nutr Phys Act 3, 22.

21. Vlismas K, Stavrinos V \& Panagiotakos DB (2009) Socioeconomic status, dietary habits and health-related outcomes in various parts of the world: a review. Cent Eur J Public Health 17, 55-63.

22. Glümer $\mathrm{C}$, Hilding-Nørkjær $\mathrm{H}$, Nordahl Jensen $\mathrm{H}$ et al. (2008) Sundhedsprofil Region Hovedstad (Health Profile for the Capital Region). http://www.regionh.dk/NR/rdonlyres/ 5D1CC89F-0F49-4585-A21B-9D68DAAD57F2/0/Forebyggels esrapport_RegionH_2010.pdf (accessed November 2008).

23. Toftegaard-Stockel J, Nielsen GA, Ibsen B et al. (2010) Parental, socio and cultural factors associated with adolescents' sports participation in four Danish municipalities. Scand J Med Sci Sports (Epublication ahead of print version).

24. Popkin BM, Duffey K \& Gordon-Larsen P (2005) Environmental influences on food choice, physical activity and energy balance. Physiol Behav 86, 603-613.

25. Lovasi GS, Hutson MA, Guerra M et al. (2009) Built environments and obesity in disadvantaged populations. Epidemiol Rev 31, 7-20.

26. Zenk SN, Schulz AJ \& Odoms-Young AM (2009) How neighborhood environments contribute to obesity. $\mathrm{Am} \mathrm{J}$ Nurs 109, 61-64.

27. Larson NI, Story MT \& Nelson MC (2009) Neighborhood environments: disparities in access to healthy foods in the US. Am J Prev Med 36, 74-81.

28. Morland K, Wing S, Diez Roux A et al. (2002) Neighborhood characteristics associated with the location of food stores and food service places. Am J Prev Med 22, 23-29.

29. Moore LV \& Diez Roux AV (2006) Associations of neighborhood characteristics with the location and type of food stores. Am J Public Health 96, 325-331.

30. Zenk SN, Schulz AJ, Israel BA et al. (2005) Neighborhood racial composition, neighborhood poverty, and the spatial accessibility of supermarkets in metropolitan Detroit. Am J Public Health 95, 660-667.

31. Zenk SN, Schulz AJ, Israel BA et al. (2006) Fruit and vegetable access differs by community racial composition and socioeconomic position in Detroit, Michigan. Ethn Dis 16, 275-280

32. Powell LM, Slater S, Mirtcheva D et al. (2007) Food store availability and neighborhood characteristics in the United States. Prev Med 44, 189-195.
33. Morland K, Wing S \& Diez Roux A (2002) The contextual effect of the local food environment on residents' diets: the atherosclerosis risk in communities study. Am J Public Health 92, 1761-1767.

34. Block D \& Kouba J (2006) A comparison of the availability and affordability of a market basket in two communities in the Chicago area. Public Health Nutr 9, 837-845.

35. Morland K \& Filomena S (2007) Disparities in the availability of fruits and vegetables between racially segregated urban neighbourhoods. Public Health Nutr 10, 1481-1489.

36. Galvez MP, Morland K, Raines C et al. (2008) Race and food store availability in an inner-city neighbourhood. Public Health Nutr 11, 624-631.

37. Fraser LK, Edwards KL, Cade J et al. (2010) The geography of fast food outlets: a review. Int $J$ Environ Res Public Health 7, 2290-2308.

38. Block JP, Scribner RA \& DeSalvo KB (2004) Fast food, race/ ethnicity, and income: a geographic analysis. Am J Prev Med 27, 211-217.

39. Lewis LB, Sloane DC, Nascimento LM et al. (2005) African Americans' access to healthy food options in South Los Angeles restaurants. Am J Public Health 95, 668-673.

40. Powell LM, Chaloupka FJ \& Bao Y (2007) The availability of fast-food and full-service restaurants in the United States: associations with neighborhood characteristics. Am J Prev Med 33, 4 Suppl., S240-S245.

41. Beaulac J, Kristjansson E \& Cummins S (2009) A systematic review of food deserts, 1966-2007. Prev Chronic Dis 6, A105.

42. Burns CM \& Inglis AD (2007) Measuring food access in Melbourne: access to healthy and fast foods by car, bus and foot in an urban municipality in Melbourne. Health Place 13, 877-885.

43. Pearce J, Blakely T, Witten K et al. (2007) Neighborhood deprivation and access to fast-food retailing: a national study. Am J Prev Med 32, 375-382.

44. Clarke G, Eyre H \& Guy C (2002) Deriving indicators of access to food retail provision in British cities: studies of Cardiff, Leeds and Bradford. Urban Studies 39, 2041-2060.

45. Apparicio P, Cloutier MS \& Shearmur R (2007) The case of Montreal's missing food deserts: evaluation of accessibility to food supermarkets. Int J Health Geogr 6, 4 .

46. Smoyer-Tomic K (2006) Food deserts in the prairies? Supermarket accessibility and neighborhood need in Edmonton, Canada. Prof Geogr 58, 307-326.

47. Smoyer-Tomic KE, Spence JC, Raine KD et al. (2008) The association between neighborhood socioeconomic status and exposure to supermarkets and fast food outlets. Health Place 14, 740-754.

48. Winkler E, Turrell G \& Patterson C (2006) Does living in a disadvantaged area mean fewer opportunities to purchase fresh fruit and vegetables in the area? Findings from the Brisbane food study. Health Place 12, 306-319.

49. Macintyre S, McKay L, Cummins S et al. (2005) Out-ofhome food outlets and area deprivation: case study in Glasgow, UK. Int J Behav Nutr Phys Act 2, 16.

50. Cummins SC, McKay L \& Macintyre S (2005) McDonald's restaurants and neighborhood deprivation in Scotland and England. Am J Prev Med 29, 308-310.

51. Datamonitor (2006) Fast Food in Europe. London: Datamonitor Europe.

52. Myers H (2004) Trends in the food retail sector across Europe. Eur Retail Digest 41, 1-3.

53. Danish National Consumer Agency (2007) Danskernes adfærd og vaner på fødevaremarkedet (Danish food habits and purchasing behavior). In Danish Consumer Report 2007, pp. 1-178. Copenhagen: Danish National Consumer Agency.

54. Kangas O (2007) Relative to what? Crossnational picture of European poverty measured by regional, national and European standards. Eur Soc 9, 119-145. 
55. Center for Statistics (2010) Population Facts and Statistics. http:// www.kk.dk/sitecore/content/Subsites/CityOfCopenhagen/ SubsiteFrontpage/ContactsAndFacts/Statistics/Cars\%20for\%20 private\%20use.aspx (accessed April 2010).

56. Statistics Bank Denmark (2010) Population and elections. BEF44: Population 1st January, by urban areas. http:// www.statbank.dk/BEF44 (accessed April 2010).

57. Hussain M (2007) Muslims in the EU: Cities Report: Preliminary Research Report and Literature Survey. Budapest: Open Society Institute.

58. Møller-Jensen L (1998) Assessing spatial aspects of school location-allocation in Copenhagen. Geogr Tidsskr 98, 71-80.

59. Messmer H \& Rosenbrink B (2006) Danskerne spiser sundere fastfood (Danes eat healthier fast food). http://www.horesta.dk/ da-dk/Om\%20HORESTA/HORESTAs\%20medier/ /media/ Filer/Materialer/tendens/Fastfood1106.ashx (accessed March 2010).

60. Fagt S (2004) Udvikling i uregelmæssige måltider og indtag af fastfood blandt børn og unge (Insight into meal-skipping and intake of fast food among children and adolescents). http:// www.food.dtu.dk/Default.aspx?ID $=21690$ (accessed March 2010).

61. Experian Denmark (2006) CD Direct Online Market Guide. http://www.experian.dk/produkter/cd-direct.html (accessed December 2008).

62. European Commission (2005) List of NACE codes. http:// europe.eu.int/comm/competition/mergers/cases/index/nace_ all.html (March 2005).

63. Stockmann Group (2007) Supermarket Yearbook. Asnæs: Retail Institute Scandinavia.

64. Gardner W, Mulvey EP \& Shaw EC (1995) Regression analyses of counts and rates: Poisson, overdispersed
Poisson, and negative binomial models. Psychol Bull 118, 392-404.

65. Charreire H, Casey R, Salze P et al. (2010) Measuring the food environment using geographical information systems: a methodological review. Public Health Nutr 13, $1773-1785$.

66. US Census Bureau (2005) Geographic Areas Reference Manual (GARM). http://www.census.gov/geo/www/ garm.html (accessed April 2010).

67. Inagami S, Cohen DA, Finch BK et al. (2006) You are where you shop: grocery store locations, weight, and neighborhoods. Am J Prev Med 31, 10-17.

68. Inagami S, Cohen DA, Brown AF et al. (2009) Body mass index, neighborhood fast food and restaurant concentration, and car ownership. J Urban Health 86, 683-695.

69. Matthews SA, Moudon AV \& Daniel M (2009) Work group II: Using Geographic Information Systems for enhancing research relevant to policy on diet, physical activity, and weight. Am J Prev Med 36, 4 Suppl., S171-S176.

70. Holstein BE, Currie C, Boyce W et al. (2009) Socioeconomic inequality in multiple health complaints among adolescents: international comparative study in 37 countries. Int J Public Health 54, Suppl. 2, 260-270.

71. Fukuda-Parr S, De Gregorio C, Fu H et al. (2004) Human Health Report 2004: Cultural Liberty in Today's Diverse World. New York: United Nations Development Programme.

72. Sundquist J, Bajekal M \& Johansson SE (1997) The UPA (underprivileged area) score and mortality in Swedish municipalities. Scand J Prim Health Care 15, 203-209.

73. Cummins S \& Macintyre S (1999) The location of food stores in urban areas: a case study in Glasgow. Br Food $\mathrm{J}$ 101, 545-553. 